ISSN: $1130-3743$

\title{
ALGUNAS APORTACIONES TEÓRICAS A LA INFLUENCIA DE LA TELEVISIÓN EN EL PROCESO DE SOCIALIZACIÓN DE LA INFANCIA
}

\author{
Some Theoretical Contributions to the Influence \\ of Television on the Process of Socialization of Childhood
}

\section{Quelques contributions théoriques à l'influence de la télévision dans le processus de socialisation de l'enfance}

\section{Piedad María SAHUQuillo MATEO}

Universidad de Valencia. Facultad de Filosofía y Ciencias de la Educación. Departamento de Teoría de la Educación. Avda. Blasco Ibáñez, 30.46010 Valencia.Correo-e: piedad.sabuquillo@uv.es

Fecha de recepción: enero de 2007

Fecha de aceptación definitiva: abril de 2007

BIBLID [(1130-3743) 19, 2007, 191-224]

\section{RESUMEN}

En el presente artículo tratamos de abordar y precisar, desde una perspectiva teórica de la educación, la complejidad del fenómeno televisivo y su influencia en el proceso de socialización de los más pequeños, por ser estos segmentos especialmente vulnerables e influenciables. Para ello, centramos nuestra atención en aquellos enfoques teóricos que, en mayor medida, han dedicado sus esfuerzos a la explicación de dicho fenómeno en relación al proceso de socialización: teoría del aprendizaje social, teoría de la aculturación, usos y gratificaciones. De este modo, podremos profundizar, en la línea ya apuntada, en el conocimiento de esta realidad de forma global, ya que no se trata de una actividad que pueda definirse desde compartimentos estancos. 
Palabras clave: proceso de socialización, infancia, teorías sobre la televisión, educación.

\section{SUMMARY}

In this article we try to deal with and determine, from a theoretical perspective of education, the complexity of the television phenomenon and its influence on the process of socialization of children and adolescents, since these segments are specially vulnerable and easily influenced. To that end, we focused our attention on those theoretical approaches that, to a greater extent, have dedicated their efforts to the explanation of this phenomenon in relation to the socialization process: theory of social learning, cultivation theory, uses and gratifications. In this way, we will be able to go deeper into the knowledge of this reality as a whole in the line already indicated, since it is not an activity that can be defined from limited compartments.

Key words: socialization process, childhood, television theories, education.

\section{SOMMAIRE}

Dans cet article on abordera et précisera la complexité du phénomène de la télévision et de son influence sur le processus de socialisation des enfants et des adolescents -étant donné que ce sont des segments de la population notamment vulnérables et influençables-, d'après une approche théorique de l'éducation. Avec cet objectif, notre intérêt sera porté sur les approches théoriques ayant expliqué ce phénomène par rapport au processus de socialisation: théorie de l'apprentissage social, théorie de l'acculturation, us et gratifications. On approfondira ainsi la connaissance de cette réalité d'une manière globale puisqu'il ne s'agit pas d'une activité que l'on puisse définir à partir de compartiments étanches.

Mots clés: processus de socialisation, enfance, théories sur la télévision, éducation.

\section{INTRODUCCIÓN}

Los medios de comunicación (y en concreto la televisión) constituyen parte importante del proceso de socialización de la infancia de nuestro tiempo. Sin duda, el medio televisivo se ha convertido en una fuente primaria común de socialización e información cotidiana, trascendiendo barreras históricas de movilidad y cultura para lo que antes eran poblaciones heterogéneas. En este sentido, la preocupación por los efectos generados en las personas por la televisión, su contribución al proceso de socialización de los más jóvenes, la posible dependencia e influencia en el rendimiento escolar así como en las relaciones interpersonales, han constituido el eje central de numerosas investigaciones desde sus inicios. 
Para la realización de nuestro trabajo, centramos nuestra atención en tres perspectivas teóricas diferenciadas (pero orientadas a un mismo objeto de estudio) que, si bien se ubican en el marco del estudio de la influencia televisiva, lo hacen desde la investigación más compleja, analizando cómo influye dicho medio en el proceso de socialización, con una perspectiva a medio-largo plazo (teoría social cognitiva y teoría del cultivo). Junto a éstas, recogemos los planteamientos de la teoría de usos y gratificaciones, desde los que se analizan los efectos socializadores del medio televisivo a la par que se considera a la audiencia, al sujeto, no como paciente sino como agente del proceso mediático. Estas tres teorías son "de referencia obligada en cualquier estudio sobre los medios" (Lucas et al., 1999, 233), y aunque no pretendemos con ello plantear que éstas sean las únicas aportaciones que se han realizado a este campo, sí son las más relevantes para nuestro trabajo.

Tomando en cuenta las diferencias teórico-metodológicas, las aparentes contradicciones iniciales desaparecen, pues se trata de adoptar una perspectiva amplia y ecléctica que permita tener presentes las distintas aportaciones. Una postura ecléctica donde tengan cabida las diferentes ideas subyacentes a las mismas, pues comprender la influencia mediática en el proceso socializador requiere, desde nuestros planteamientos, adoptar una perspectiva integradora en pro de una mayor y mejor comprensión del objeto de estudio que nos ocupa, contribuyendo así a la toma de decisiones pedagógicas para la optimización de la realidad. Es por esto que consideramos necesario recoger aquellas aportaciones que analizan los efectos que producen los medios de comunicación (concretamente la televisión), pero también aquellas que se centran en el uso que de ellos hacen los telespectadores.

Estamos de acuerdo con Wolf $(1987$ y 1994, 30) cuando plantea "la idea de una evolución lineal, de un progreso constante, acumulativo en el conocimiento de estos problemas [...] la reconstrucción de la investigación por coexistencia [...] pone más de relieve la complejidad del campo, la interdependencia entre modelos". Así, nuestros planteamientos caminan en esta línea pues partimos de la convicción de que la realidad humana y social es una realidad compleja, de modo que para poder mejorar dicha realidad hemos de considerar en nuestra actuación pedagógica aportaciones procedentes de diversos ámbitos que puedan enriquecer nuestro trabajo.

2. Teoría del aprendizaje SOcial, teoría del CUltivo Y teoría de usos Y GRATIFICACIONES: MODELOS DE ANÁLISIS SOBRE LA INFLUENCIA DE LA TELEVISIÓN EN EL PROCESO DE SOCIALIZACIÓN

Podemos afirmar que el comienzo del proceso de socialización se sitúa en el mismo momento del nacimiento del menor, y va desarrollándose cuando entra en contacto con su familia, el grupo de iguales, la escuela, los medios de comunicación y todo el resto de instancias con que el ser humano se relaciona. Rocher (1985, 133) define la socialización como 
el proceso por cuyo medio la persona humana aprende e interioriza, en el transcurso de su vida, los elementos socio-culturales de su medio ambiente, los integra a la estructura de su personalidad, bajo la influencia de experiencias y de agentes sociales significativos, y se adapta así al entorno social en cuyo seno debe vivir.

Sin duda, el mayor impacto del proceso de socialización ocurre en los primeros años de vida, por la inmadurez y la indeterminación biológica que los caracteriza. Giddens (1995) afirma al respecto que la socialización es el proceso por el que el niño indefenso se va convirtiendo en una persona capaz de conocer, ducha en las formas de la cultura en la que ha nacido. Es entonces cuando se sientan las bases de la personalidad del ser humano, aunque la duración de este proceso abarca la totalidad del ciclo vital. En la misma línea, Berger y Berger (1979) plantean que la socialización es el proceso por el que un individuo aprende a convertirse en miembro de la sociedad. Por ende, el objetivo final de la educación sería precisamente construir ese ser social en cada uno de nosotros (Durkheim, 1976).

Sin embargo, hemos de plasmar también aquí la necesidad de entender el proceso de socialización como proceso bidireccional (Elías, 1990), pues el agente social es al mismo tiempo una construcción social y construye la sociedad. Es agente de su propia realidad. Así, para Ritzer (1996, 307)

la socialización es la adquisición de la competencia para la interacción [...] Los niños no son receptáculos pasivos, incompletos; antes bien, son participantes activos en el proceso de socialización porque disponen de la capacidad de razonar, idear y adquirir conocimientos.

En palabras de Vander Zanden $(1990,126)$ la socialización «es el proceso por el cual los individuos, en su interacción con otros, desarrollan las maneras de pensar, sentir y actuar que son esenciales para su participación eficaz en la sociedad". Se entiende entonces como proceso interactivo, necesario al niño y al grupo social donde nace, a través del cual el ser humano satisface sus necesidades y asimila la cultura, a la vez que, recíprocamente, la sociedad se perpetúa (Palacios, Marchesi y Coll, 1995). Qué duda cabe, entonces, que el conocimiento social es premisa de toda educación, y que este proceso está totalmente vinculado a la subjetividad, a los grupos de pertenencia, a los esquemas mentales previos, etc. (Escámez y Ortega, 1986).

En un mismo orden de cosas, Thompson (1998) afirma que comprenderemos mejor el impacto social de los medios de comunicación si descartamos la idea de que sólo sirven para transmitir información a personas cuyas relaciones con los otros se mantienen inmóviles, pues los medios de comunicación implican nuevas formas de interacción en la sociedad, nuevas maneras de relacionarse con los otros y con uno mismo. Así, nuestros niños conviven a diario con el medio televisivo, hacen uso del mismo para sus vidas, ejerciendo éste una influencia determinante en su desarrollo personal y social, tal y como se corrobora desde las diferentes perspectivas teóricas que a continuación analizamos. 
Cabe señalar que las perspectivas teóricas recogidas en este artículo, si bien a priori responden a planteamientos diferentes, consideramos que no han de ser entendidas como aportaciones excluyentes sino complementarias, pues de este modo podremos realizar un análisis en mayor profundidad.

\subsection{Teoria del aprendizaje social}

Tal y como señala Huertas (2002), las investigaciones sobre los procesos de socialización están estrechamente relacionadas con los modelos de aprendizaje social, con la teoría del aprendizaje vicario de Bandura, pues esta teoría parte de la convicción de que la influencia de la televisión no es algo inmediato y directo, sino que acontece como proceso. La teoría social del aprendizaje se originó, fundamentalmente, a raíz de los estudios sobre los efectos violentos de la televisión en las conductas infantiles. Así, "uno de los debates más antiguos responde a la cuestión de si la televisión y la exposición a los medios de comunicación, sobre todo en relación a la violencia, produce en los individuos una catarsis o una incitación" (Wimmer y Dominick, 1996, 365). Los defensores de la idea de catarsis afirman que la contemplación u observación de actuaciones y expresiones agresivas en la televisión reduce la agresividad por un mecanismo de purga de los impulsos violentos, mientras que los detractores de esta postura afirman que la violencia televisiva constituye un estímulo que incita a actuar del mismo modo pues la observación de imágenes violentas promueve mayores niveles de agresión.

En este sentido, la aproximación teórica de la teoría social del aprendizaje sobre los efectos de los medios de comunicación procede de los psicólogos behavioristas, siendo desarrollada en el campo de los medios de comunicación por el psicólogo social Albert Bandura. Así, esta teoría surge, principalmente, a partir de la aplicación de la Teoría del Aprendizaje Social o Aprendizaje por Observación a las contingencias de los medios de comunicación de masas, a partir de cuyos postulados se han ido desarrollando distintas aportaciones e investigaciones. Así, Bandura (1977) afirma que las personas aprenden tanto a partir de su experiencia directa como de su observación, a través de lo que él denomina "modelado". Este autor plantea que existen unos elementos claves que intervienen en el aprendizaje por observación como son la atención, la retención, la reproducción motriz y la motivación.

Una idea fundamental de esta teoría se basa en que los niños, a lo largo de su proceso de desarrollo personal y social, imitan los modelos que ven, en el caso que nos ocupa, a través de la televisión, pues van interiorizando tanto conductas como actitudes que presencian en la televisión. Los niños van aprendiendo la mayor parte de sus comportamientos a través de la imitación de modelos, pues de no ser así, resultaría altamente costoso realizar un aprendizaje diferente para cada situación. Es decir, el modelado simbólico es de gran importancia, pues hace aumentar las posibilidades experienciales de los niños que de otro modo no podrían alcanzarse 
personalmente, ya que a lo largo de nuestra vida solamente tenemos contacto con un limitado y pequeño sector del entorno social y físico. De este modo, el autor plantea el principio del aprendizaje social, mediante el cual el ser humano es capaz de aprender nuevos comportamientos observando a otras personas o modelos. Si el conocimiento y la habilidad se pudieran adquirir sólo a través de la experiencia directa, el proceso de desarrollo humano sufriría un enorme retraso, por no mencionar los elementos de peligro y tedio. Los humanos han desarrollado una capacidad avanzada para el aprendizaje a partir de la observación, que les permite incrementar sus conocimientos y habilidades a partir de la información recibida de las influencias modeladoras. En efecto, la inmensa mayoría de fenómenos de aprendizaje resultantes de experiencia directa pueden producirse de manera subsidiaria por medio de la observación del comportamiento humano y de sus consecuencias (Rosenthal y Zimmerman, 1978).

En este sentido, cabe plantear la gran importancia del modelado simbólico. La gran relevancia del modelado simbólico reside en su enorme poder multiplicativo, pues en el aprendizaje observacional un único modelo puede transmitir nuevos modos de pensamiento y de comportamiento simultáneos a mucha gente en lugares muy dispersos, como ocurre a través de la televisión, pues en el transcurso de la vida diaria, los seres humanos sólo tienen contacto con un pequeño sector del entorno social y físico en que viven. $Y$ así, cuanto más dependen las imágenes de la realidad del entorno simbólico mediático, mayor es el impacto social (BallRokeach y DeFleur, 1976). Junto a esto, el crecimiento acelerado de la tecnología ha expandido de manera vasta el espectro de modelos a los que se expone diariamente la sociedad. Así, las prácticas sociales y las nuevas ideas se difunden hoy día con enorme rapidez, a través del modelo simbólico, ya sea dentro de una sociedad o de un colectivo a otros (Bandura, 1986). El proceso de adquisición es vital para la supervivencia, así como para el desarrollo humano, porque el potencial natural no integra demasiadas habilidades innatas y los errores pueden ser peligrosos. Asimismo las limitaciones de tiempo, de recursos y de movilidad reducen seriamente las situaciones y actividades que pudieran ser exploradas directamente con objeto de adquirir un nuevo conocimiento o nuevas competencias. De este modo, a diferencia de las teorías clásicas del aprendizaje, en este caso se demuestra la posibilidad de lograr el desarrollo de conductas nuevas mediante la observación de un modelo atractivo (Bandura, 1983). Estas conductas aprendidas tendrán una alta probabilidad de reproducirse en el individuo, tanto en contextos similares al de la conducta modelo, como en nuevas circunstancias en donde el patrón pueda generalizarse.

La teoría cognitiva social atribuye una importancia central a los procesos cognitivos, vicarios, autorregulativos y autorreflexivos. Los seres humanos están dotados de una gran capacidad para simbolizar por medio de una herramienta muy poderosa que les hace comprender su entorno, les da capacidad para crearlo y regularlo, con lo cual pueden virtualmente retocar cualquier aspecto de sus vidas. La mayoría de influencias externas afectan al comportamiento a través de procesos cognitivos. Así, el ser humano procesa y transforma experiencias transitorias por 
medio de símbolos para su posterior formación de modelos cognitivos que le servirán como modelo de juicio y de actuación: a través de los símbolos podemos dar significado, forma y continuidad a las experiencias que hemos tenido. El ser humano no solamente sabe y ejecuta, sino que también autorreacciona con una capacidad de autodirección. La autorregulación de afecto, motivación y acción, funciona, en parte, por medio del estándar interno y de las reacciones de evaluación del propio comportamiento (Bandura, 1989). Cuando se ha adoptado un estándar de moralidad, las sanciones autoimpuestas para las acciones que se ajustan a sus estándares personales o que los violan sirven como reguladores de influencia (Bandura, 1991). En general, estas actividades metacognitivas alimentan un pensamiento verídico, pero también pueden producir patrones de pensamiento defectuosos. Las acciones de impacto que se derivan de creencias erróneas crean a menudo entornos sociales que confirman dichas creencias (Snyder, 1980). La comprobación del pensamiento, por comparación con versiones televisivas distorsionadas de la realidad social, puede albergar falsedades compartidas sobre los humanos, los lugares o las cosas. La comprobación social puede albergar extraños puntos de vista sobre la realidad si las creencias compartidas del grupo referente al que uno está afiliado son peculiares y el grupo carece de ataduras sociales o de influencias exteriores (Bandura, 1982).

También, el mecanismo de autoeficacia desempeña un papel central en la actuación humana (Bandura, 1986, 1989). Las creencias humanas acerca de su eficacia personal influyen sobre las acciones elegidas, sobre la cantidad de esfuerzo que quieren invertir en dichas actividades, sobre el plazo de tiempo que desean perseverar si aparece un obstáculo y sobre su resistencia. Del mismo modo, la probabilidad de reproducción estará en función de las consecuencias observadas en la conducta modelo, así como en la atribución que el sujeto haga de las posibles reacciones del medio a su conducta en cada caso particular (Bandura, 1997). Basado en esta concepción de aprendizaje, Bandura desarrolla una detallada explicación del proceso concreto de incorporación de conductas agresivas en el ser humano (Bandura, 1983). En este sentido, debemos tener presente la importancia de las consecuencias que se derivan de una conducta, pues si éstas son graves tenderemos a inhibir los actos y, si son favorables, las realizaremos sin ningún temor. Sin embargo, no es lo mismo vivir las consecuencias en nuestra propia vida que poder estar expuestos a que la televisión maquille las mismas, pues incluso ocurre en ocasiones que se da una justificación de los actos incorrectos, frente a las sanciones sociales que también pueden aparecer en el trasfondo de las imágenes y mensajes.

No debemos olvidar el problema que puede suponer el hecho de que los individuos percibamos visiones televisivas distorsionadas, donde puedan aparecer incluso falsedades en relación a las personas, los lugares, las cosas, las relaciones interpersonales, etc. Ante estos planteamientos, consideramos que la televisión encierra un potencial peligro que responde al hecho de que constantemente se sigue presentando a través de la misma un mundo mayoritariamente "dominado" 
por hombres blancos y jóvenes, degradando en numerosas ocasiones a la mujer, los ancianos, los extranjeros, etc., pese a los cambios positivos que han ido aconteciendo (Hoffman et al., 1995). Del mismo modo, el comportamiento transgresor se regula por medio de dos bloques principales de sanciones: las sanciones sociales y las internas. Cuando emanan sanciones sociales, el individuo reprime la transgresión porque puede anticipar que dicha conducta le acarreará la censura social y otras consecuencias adversas. Cuando se dan motivadores enraizados en un control autorreactivo, el individuo refrenará el deseo de transgresión porque su conducta le llevaría al autorreproche. Las descripciones mediáticas pueden alterar las sanciones percibidas. Por ejemplo, a menudo se muestra una agresión televisada de tal manera que tiende a debilitar la represión de una conducta agresiva (Goranson, 1970). Los efectos inhibidores y desinhibidores que emanan de estas autosanciones están vastamente condicionados por mecanismos autorreguladores. Los mecanismos autorregulativos no entran en funcionamiento a menos que sean activados de antemano y existen muchos procesos por medio de la conducta inhumana (Bandura, 1991). Un conjunto de prácticas de desactivación opera sobre la conformación del propio comportamiento por medio de la justificación moral. Normalmente, el ser humano no se dedica a la práctica de una conducta reprensible hasta que no se ha justificado a sí mismo la moralidad de sus acciones. Del mismo modo, los juicios morales de conducta también están parcialmente influidos por aquello frente a lo que se les compara. Los actos autodeplorables pueden trocarse en virtuosos si se contrastan con transgresiones más flagrantes. También las etiquetas eufemísticas ${ }^{1}$ son otro instrumento conveniente para enmascarar actividades reprensibles o incluso otorgarles un estatus respetable. Ball-Rokeach (1972) concedió un significado especial a las reacciones evaluativas y a las justificaciones sociales presentadas en los mass media, en particular a los conflictos de poder.

De este modo, la teoría social cognitiva explica la función psicosocial a partir de tres aspectos relacionados entre sí: el comportamiento, los factores personales (tanto biológicos como cognitivos) y los eventos ambientales. Debemos tener en cuenta que debido a la naturaleza bidireccional de la influencia, el ser humano es producto y productor de su entorno. De modo que ni todos los factores ejercen la misma influencia, ni se trata de un efecto inmediato. Antes bien, se precisa de un tiempo para poder desarrollar dichos efectos. Así, por medio de la manipulación simbólica de la información derivada de experiencias personales y vicarias, el ser humano comprende el funcionamiento de las relaciones causales y expande su conocimiento.

Por todo lo anteriormente explicado, cabe destacar aquí cuáles son los cuatro principales procesos por los que se rige el aprendizaje observacional: la atención (determina el contenido selectivamente observado en la profusión de influencias modeladoras y el contenido de información extraída de los eventos modelados en

\footnotetext{
${ }^{1}$ En el sentido de no "llamar a las cosas por su nombre".
} 
curso); el recuerdo (un evento que no se recuerda es un evento poco influyente. Nos referimos aquí a los procesos representacionales cognitivos, pues el proceso de retención conlleva una actividad transformadora y una información reestructuradora); la producción comportamental (este proceso se efectúa por medio de un igual dado de conceptos que guían la construcción y la ejecución de patrones de conducta y donde la idoneidad de la acción se compara con el modelo conceptual) y la motivación (el ser humano tiene más capacidad para exhibir un comportamiento modelado si su resultado tiene un efecto valorado que si se consigue un efecto poco gratificante o punitivo).

Bandura (1977) afirma que si una conducta antisocial en los niños recibe un refuerzo positivo será más fácil que la continúen repitiendo por ser efectiva para ellos. Sin embargo, "el comportamiento imitativo de actos negativos puede ir asociado a otros factores como el grado de cercanía con la realidad percibido en las acciones observadas, excitación emocional experimentada, o presencia de otros estímulos ambientales que pudieran incitar al comportamiento antisocial" (Wimmer y Dominick, 1996, 366). La modelación no es un mero proceso de conducta mimética. Un gran porcentaje del aprendizaje humano se dirige hacia el desarrollo de las habilidades cognitivas a fin de adquirir y utilizar conocimientos para el futuro. La habilidad de pensar adquirida por métodos de observación se facilita con la utilización de modelos verbales que emiten estos pensamientos en voz alta al tiempo que integran actividades resolutorias de problemas (Meichenbaum, 1984).

La adquisición de nuevas reglas generativas a partir de la información modelada está conformada por, al menos, tres procesos: extracción de características determinantes a partir de varios ejemplos sociales, integración de la información extraída del reglamento compositivo y utilización del reglamento para producir nuevos ejemplos de comportamiento. A través de la modelación abstracta el ser humano adquiere, entre otras cosas, un estándar que le permite categorizar y juzgar eventos, reglas de comunicación lingüística, habilidad de pensamiento en beneficio de su conocimiento, estándares personales que regulan la conducta y motivación propias (Bandura, 1986; Rosenthal y Zimmerman, 1978). Desde esta perspectiva, Bandura ${ }^{2}$ nos plantea que las imágenes transmitidas a través de la televisión constituyen una situación por demás favorable para el desarrollo del aprendizaje por modelaje, puesto que los argumentos están generalmente planificados para lograr la identificación del televidente con determinados personajes, que se convierten así en modelos a imitar, y cuyas conductas se presentan dentro de un contexto que facilita a su vez la identificación de sus consecuencias personales y sociales (Bandura, 1994). Las representaciones televisivas de las realidades sociales reflejan las tendencias ideológicas en sus descripciones de la naturaleza humana, de las relaciones sociales y de las normas y estructuras sociales.

${ }^{2}$ A partir de los diferentes estudios que ha venido realizando. 
En suma, las influencias de los modelos actúan de diversos modos: como tutores, inhibidores, desinhibidores, apuntadores sociales, incitadores de emociones y realzan además los valores y concepciones de la realidad, que pueden funcionar separadamente pero que a menudo lo hacen en conjunto. Las influencias mediáticas crean atributos personales además de alterar los preexistentes (Bandura, 1986). El juicio, los valores y la conducta humana pueden alterarse por un modelo televisivo, sin tener que esperar a la llegada de un intermediario influyente para adoptar lo que se ha visto y actuar luego como difusor. Chaffee (1982) aportó abundantes evidencias que cuestionan la opinión predominante de que las fuentes de información interpersonal son, por definición, más persuasivas que las mediáticas. El ser humano busca la información que le puede ser útil a través de distintas fuentes, y el grado de utilización de estas fuentes depende en gran parte de su accesibilidad y de la probabilidad de que aporten la información deseada.

La modelación televisiva se utiliza hoy en día para efectuar el cambio social a nivel de comunidades y a nivel de la sociedad en general (Bandura, 1986; Singhal y Rogers, 1989). Los mass media, en particular la televisión, son la mejor puerta de acceso al público debido a su gran poder de captación. Por este motivo, la televisión se utiliza cada vez más como vehículo principal de justificación. Los medios electrónicos se emplean cada vez con mayor frecuencia para presentar confrontaciones que legitimen y capten apoyo para la propia causa y desacrediten al oponente (Bandura, 1990). El ser humano se comportará de una forma que en circunstancias normales repudiaría si se encuentra ante una autoridad legítima que sanciona su conducta y que acepta la responsabilidad de sus consecuencias (Milgram, 1974). Bajo condiciones de "desplazamiento de responsabilidad" el ser humano considerará que sus actuaciones provienen de los dictámenes de otros, no de su propia responsabilidad personal. Puesto que no es el agente activo de sus actos, no sufrirá reacciones prohibitivas. Bajo condiciones de responsabilidad difusa, el ser humano se comporta de un modo mucho más ofensivo que cuando tiene que rendir cuenta de sus actos personalmente (Bandura, Underwood y Fromson, 1975).

Del mismo modo, esta teoría plantea que incluso la exposición reiterada a acciones socialmente perjudiciales puede conllevar una mayor probabilidad de que las personas repitan esas acciones (Wimmer y Dominick, 1996, 365). Sin duda, esta idea enlaza directamente con el concepto de insensibilización que tanto se ha venido trabajando en los últimos tiempos desde diferentes perspectivas, idea que viene a decir que las personas que constantemente se encuentran expuestas a mayores dosis de violencia acaban mostrando una preocupación menor por estas conductas antisociales. Las investigaciones en las que distintos factores de liberación han sido sistemáticamente modificados en representaciones mediáticas de actos inhumanos dan testimonio del poder desinhibidor de las influencias de los medios (Meyer, 1972).

Por otra parte, las expresiones emocionales de otros incitan fácilmente al ser humano. La excitación subsidiaria se efectúa mayormente por medio de un 
proceso de autoiniciación, es decir, viendo a otros reaccionar emocionalmente promueve condiciones activadoras de pensamientos e imágenes que causan emoción en el observador. A medida que el ser humano desarrolla su capacidad de autoincitación cognitiva, puede generar reacciones emocionales a apuntes que, en principio, sólo eran experiencias de un modelo emocional. Sin duda, aquello que realmente da significado a la influencia vicaria es la actitud durable que puede adoptar el observador, así como sus reacciones emocionales o la proclividad de su comportamiento hacia otras personas, lugares o cosas asociados a experiencias del modelo emocional. Aprenden a temer aquello que había asustado a los modelos, a repudiar lo que había causado repulsión a los modelos y a querer lo que les había gratificado (Bandura, 1986). Cuanto más fuerte sea la eficacia del sentido de superación imbuido, más audaz será el comportamiento (Bandura, 1982).

Como mejor se define la influencia televisiva es en términos del contenido de visionado realmente llevado a cabo, y no en función de la mera cantidad de horas de presencia ante un televisor encendido. Las mediciones de exposición televisiva más particularizadas demuestran que un visionado televisivo muy intenso tiene como consecuencia la reconformación de las concepciones y creencias sobre la realidad del espectador (Hawkins y Pingree, 1982). Los estudios controlados en laboratorio evidencian que las construcciones televisivas conforman las creencias del espectador. En efecto, muchos conceptos erróneos compartidos sobre objetivos profesionales, grupos étnicos, minorías, la tercera edad, roles sociales y sexuales y otros aspectos vitales son aculturaciones en parte debidas a los estereotipos de los modelos simbólicos (Buerkel-Rothfuss y Mayes, 1981). Así, la influencia de los modelos sobre la actuación, canalización y soporte del comportamiento ajeno, está extensamente documentada en estudios tanto de laboratorio como de campo (Bandura, 1986). Las acciones de los modelos adquieren el poder de activar y canalizar comportamientos cuando, a los ojos de los observadores, son buenos predictores de que actuando de manera similar obtendrán resultados positivos.

Por lo que se refiere a los métodos utilizados desde esta perspectiva, tanto los experimentos como las encuestas han sido los más populares a la hora de determinar el impacto de los medios en los comportamientos sociales, tanto positivos como negativos. Sin duda, "los trabajos de laboratorio han mostrado una asociación positiva más fuerte entre el consumo de violencia audiovisual y la manifestación de agresividad" (Bandura, 1996, 365). La teoría de Bandura ha continuado estando sometida a distintos análisis que han conllevado avances en relación a la misma y nuevas aportaciones como las sugeridas por Tannenbaum y Zillman (1975) al plantear la hipótesis de la activación, desde donde se afirma que para que una imagen conlleve un efecto demostrable es necesario que aumente la activación despertada en el individuo, pudiendo dar paso a la "transferencia de la excitación" (término acuñado por estos especialistas) al poderse situar la persona ante una incitación reavivadora y moverse en circunstancias en las que la respuesta antisocial es factible. Sin embargo, no sólo sucede esto ante los efectos negativos, sino que, también, 
el comportamiento cívico ${ }^{3}$ parece que se activa mediante la inducción mediática de un revulsivo, siendo las personas que llegan a una gran excitación las que se muestran más predispuestas a la realización de acciones de solidaridad social.

Diferentes autores han comprobado la aplicabilidad de la teoria del aprendizaje social a diferentes campos en relación a los efectos de las imágenes, como son las imágenes sexuales (Zillman y Bryant, 1982). Linz y sus colaboradores (1984) realizaron diferentes estudios a través de los que descubrieron que los hombres que habían visto cinco películas con imágenes combinadas de erotismo y violencia contra mujeres percibían menor grado de violencia y de circunstancias degradantes para las mujeres en ciertas escenas que la sensación experimentada por un grupo de control que no había visto esas películas.

La importancia de la televisión para esta teoría hace su aparición cuando este medio de comunicación se convierte en una fuente de aprendizaje mediante la observación (o aprendizaje observacional) de los modelos y conductas expuestas en la pantalla. Sin embargo, para que los receptores aprendan a partir de los contenidos expuestos en la televisión, se han de seguir una serie de pasos (Jeffres, 1986): el individuo debe estar expuesto al contenido de los medios de comunicación e, igualmente, prestar atención al mismo; el sujeto en cuestión debe ser capaz de recordar la conducta que ha observado y pensar sobre ella: repetición cognitiva; la persona debe poseer la habilidad cognitiva y la motivación suficiente para poner en práctica la conducta que ha aprendido. La motivación se mantiene mediante algún tipo de reforzamiento interno o externo que incita a la realización o imitación de dicha conducta.

Los investigadores sociales han analizado otra serie de variables (además de la edad y el sexo que también son importantes) con el propósito de conocer hasta qué punto influyen éstas en el proceso de imitación de ciertos modelos aparecidos en la pequeña pantalla, así como para descubrir qué conductas tienen más posibilidades de ser imitadas. Entre estas variables se pueden encontrar: la similitud entre el modelo representado y el receptor; la credibilidad del modelo; el contexto en el que se encuentra el receptor; las semejanzas y diferencias entre la vida del modelo y la vida real del receptor; el estado emocional del receptor; la percepción de la realidad de lo que el receptor está observando en la televisión (Lucas et al., 1999).

Cabe señalar aquí que si bien los estudios realizados desde esta perspectiva han supuesto una importante aportación a las investigaciones sobre los efectos de la televisión, la crítica señala algunos de ellos por diferentes motivos. En este sentido, Harris (1994) indica que dichos estudios resultan excesivamente artificiales y, en este sentido, cuestiona la transferencia de los resultados. Sin embargo, este mismo autor reconoce que investigaciones más recientes en contextos reales han venido a corroborar los efectos del modelaje ejercido por la televisión (Huesmann et al., 1984).

${ }^{3}$ Socialmente adaptado. 
La activación de un esquema en la mente de los telespectadores ante el impacto de la televisión puede ser causada por alguna información concreta del programa que está viendo. Del mismo modo, puede ser provocada por ciertas características formales del medio en particular como pueden ser los flashbacks, el montaje o las repeticiones. Es curioso observar cómo los niños de menor edad no llegan a comprender el significado real de estas características formales e interpretan lo que ven de forma literal. De hecho, parte del proceso de aprendizaje del uso de los medios de comunicación, especialmente de la televisión, consiste en aprender estas características formales y saber cómo interpretarlas (Lang et al., 1993).

Desde nuestra perspectiva, tanto los planteamientos de que parte esta teoría como las críticas constructivas que se han elaborado en torno a la misma resultan de gran interés para el desempeño de la labor pedagógica. Tal y como venimos afirmando, resulta indispensable tomar en consideración distintas aportaciones que contribuyan al conocimiento en profundidad del objeto de nuestro estudio.

\subsection{Teoría del cultivo o aculturación}

La teoría del cultivo también atribuye a la televisión una función socializadora, al plantear que existe una estrecha relación entre la exposición a mensajes televisivos y las creencias y conductas de la audiencia, afectando así el medio a la concepción de la realidad (Abercrombie y Longhurst, 1998). Así, en contraposición a los planteamientos de efectos directos, una de las tradiciones de investigación más influyentes en lo referente a los efectos generados por los medios a largo plazo e indirectos es la que abordamos en este apartado de nuestro trabajo, la denominada teoría del cultivo, siendo ésta "una de las teorías más relevantes relacionadas con los efectos cognitivos de la televisión" (Lucas et al., 1999, 234).

El máximo representante de esta teoría es George Gerbner, quien inició una línea de trabajo que más tarde sería continuada por sus discípulos. Tanto de su autor principal como del equipo de investigación con el que trabaja, cabe destacar la sistematicidad por la que se caracterizan sus investigaciones así como que lo han hecho a través del tiempo (Gerbner et al., 1994). Durante más de cuatro décadas, casi desde los inicios de este medio, este científico y su equipo han desarrollado innumerables estudios sobre los efectos de la televisión en los procesos de socialización. Desde sus inicios, analizaron gran cantidad de programas a través del análisis de contenido, con el fin de contemplar en sus investigaciones, sobre todo, cuáles eran los valores que la televisión transmitía. La investigación consistía en visionar todos los programas y, a través del análisis de contenido, establecer categorías de valores que eran transmitidos.

Tal y como plantean Signorielli y Morgan (1990, 15) "el análisis de cultivo [...] investiga los procesos institucionales que subyacen en la producción del contenido de los medios, las imágenes en el contenido de los medios y las relaciones entre la exposición de los mensajes televisivos y las creencias y conductas de la audiencia". 
A diferencia de la inmensa mayoría de la bibliografía disponible, Gerbner ha realizado profundas investigaciones longitudinales, lo cual le ha permitido establecer el proceso de evolución del efecto a través del desarrollo humano, desde sus primeros años hasta la edad adulta. Además, el visionado de televisión se considera como un proceso interactivo entre mensajes y audiencias.

De acuerdo con la teoría del cultivo, la televisión tiende a transmitir sistemas de mensajes que presentan la misma lección una y otra vez, creando y reflejando así opiniones, imágenes y creencias (Lucas et al., 1999). Diversas investigaciones han venido planteando la importancia de la influencia que podían ejercer en la percepción del público las imágenes proyectadas por los medios a los que se exponían, sobre todo cuando los medios eran las principales vías de acceso a determinadas temáticas. Así, Siegel (1958) plantea cómo los niños podían tener influenciada su percepción sobre cómo se comportaban los taxistas según las informaciones que escuchaban de esta profesión por la radio. En el mismo sentido, DeFleur (1967) afirmaba que las percepciones de los niños en relación a determinadas profesiones que se mostraban habitualmente en los medios eran bastante homogéneas.

Así pues, la idea o planteamiento básico que subyace a esta teoría del cultivo o incubado cultural responde principalmente a que «la reiterada recepción de imágenes y temáticas ofrecidas de manera uniforme y sostenida por los medios terminará por afectar nuestra forma de percibir esos asuntos, moldeando nuestra percepción en consonancia con la perspectiva ofrecida por dichos medios" (Gerbner, Morgan y Signorielli, 1996, 376).

De este modo, la teoría del cultivo atribuye a la televisión una función socializadora, ya que afirma que se da una relación estrecha entre la exposición a mensajes del medio televisivo y las creencias y conductas de la audiencia. La televisión afecta a la concepción de la realidad social. Ver la televisión lleva, gradualmente, a asumir creencias sobre el mundo social que se confirman con la visión estereotipada, distorsionada y muy selectiva de la realidad, según es presentada en la ficción televisiva y las noticias.

Tal y como afirman Gerbner et al. (1979), hay dos supuestos fundamentales que están a la base de esta teoría: la televisión presenta un mundo total, compuesto de historias interrelacionadas (tanto en lo que se refiere al drama como a las noticias) y la audiencia contempla, en gran medida, la televisión de forma no selectiva. Ver la televisión es un ritual al que se atiende con regularidad. Así, esta teoría parte de la convicción de que la televisión es un instrumento cultural, una herramienta de la que todos hacemos uso a diario y que socializa a las personas tanto en conductas como en roles sociales, es decir, que afecta a la vida y desarrollo personal de los individuos, pues la televisión resulta ser una abundante fuente de imágenes y mensajes que son extensamente compartidos por la mayoría del público, cobrando cada vez más fuerza. "La televisión se materializa en un ritual diario que las élites comparten con muchos otros tipos de público [...] este sistema fomenta desde la infancia las predisposiciones y preferencias que antaño se adquirían a 
partir de otras fuentes" (Gerbner, Morgan y Signorielli, 1996, 36). Sin duda, hoy la televisión hemos de considerarla como una fuente primaria no sólo de información sino también de socialización, pues incluso traspasa las barreras de clases sociales, llevando a todos los hogares ese conjunto de imágenes y mensajes al que hacíamos referencia.

La perspectiva de la aculturación se fundamenta en la absorción de distintas actitudes y concepciones para formar una base común y estable de pensamientos e ideas. La aculturación comprende aquellos fenómenos que resultan cuando grupos que tienen culturas diferentes entran en contacto y se produce un subsiguiente cambio de la cultura original. Todos, en cierta medida, estamos dentro de este proceso de aculturación, pues si algo conseguirá la televisión es que, al exponernos reiteradamente a las imágenes y mensajes que transmite, conforma y alimenta nuestras propias ideas sobre la vida, nuestros valores y perspectivas. No cabe duda de que si algo diferencia a la televisión de otros medios es la capacidad de producir una serie de mensajes e imágenes para una población global, y consecuentemente fomentar concepciones de la realidad compartidas para públicos "a priori" muy heterogéneos. Como ya señalábamos, en palabras de Gerbner et al. "es el narrador de historias más común de nuestra era" (1996, 37).

Sin duda, la consideración de "acumulativo" es una de las más importantes en la teoría planteada por Gerbner (Wimmer y Dominick, 1996). Él mismo, junto a su equipo, denomina a este proceso acumulativo "el proceso de cultivación", pues considera en todo momento que la televisión cultiva desde la infancia una cultura estandarizada en los individuos. Una cultura que no es generada por ellos mismos a nivel individual, sino fomentada por el contexto sociocultural en que habitan. Según plantean estos investigadores, este efecto socializador será mayor y más intenso conforme aumente la exposición, tanto en cuanto a la frecuencia como en lo que respecta a la cobertura de esta frecuencia a través de toda la vida, pues como veremos más adelante en detalle, la cantidad de exposición a la televisión es considerada por Gerbner una premisa fundamental para determinar la influencia que puede ejercer sobre los individuos.

Por otra parte, desde estos planteamientos teóricos, se establece la necesidad de identificar un proceso paulatino de acriticidad y poca selectividad que caracteriza a algunos individuos. Esta última idea apuntada por Gerbner y su equipo resulta de gran interés, al tiempo que enlaza y refuerza el principio de excitabilidad planteado por Zillmann (1983). Este principio viene a significar que la audiencia será cada vez más excitable y más influenciable conforme más televisión observe, y, en este sentido, los mecanismos superiores de toma de decisión y de análisis crítico de la información planteados por otros autores, como Bandura, se ven paulatinamente debilitados, permitiendo así un proceso de aprendizaje más automático e irreflexivo. En definitiva, se plantea que la televisión influye negativamente en la toma de decisiones mediante el juicio crítico por parte de los individuos que experimentan un alto consumo de la misma. 
En este sentido, para poder llevar a cabo los estudios pertinentes y poder obtener resultados fiables, desde esta teoría, la investigación ha estado dirigida hacia dos focos de atención principalmente (McQuail y Windahl, 1997): uno orientado hacia la comprobación del planteamiento sobre la consistencia y la distorsión del "sistema de mensajes" del medio televisivo; otro dirigido a probar, mediante encuestas, las creencias del público sobre la realidad social, especialmente aquellas que pueden ser examinadas mediante indicadores empíricos. En definitiva, se trata de comprobar la vinculación existente entre las opiniones sobre la realidad con la realidad en sí, teniendo en cuenta la diversidad de grados de exposición a la televisión.

Como ya antes advertíamos, Gerbner y su equipo, a través de su plan de investigación sobre Indicadores Culturales, han ido recopilando, desde los años 60, datos sobre el contenido de los programas televisivos de Estados Unidos, para poder así analizar el impacto que tiene el alto consumo sobre la audiencia. Así, la principal hipótesis del análisis de cultivo o de incubación, tal y como afirman Gross y Morgan (1985) consiste en el hecho de que cuanto más tiempo pase una persona viendo y viviendo el mundo de la televisión, resultará mucho más fácil que exprese ideas y concepciones sobre la realidad social que están intimamente relacionadas, arraigadas en las representaciones televisivas.

Los primeros resultados de los trabajos de Gerbner y su equipo vienen a concluir que "los consumidores de mayor cantidad de horas de televisión arrojaban cifras más altas que los televidentes de bajo consumo en un índice de imagen estereotipada del mundo" (Wimmer y Dominick, 1996, 377), llegando a evidenciar cómo las personas llegan a percibir la realidad moldeada por la televisión, principalmente. A modo de ejemplo, la gente que ve más horas la televisión, que está expuesta durante más horas a la televisión, tiende ser más desconfiada y temerosa en las relaciones con los demás (Gerbner et al., 1978).

Por otra parte, el equipo a cuyo frente se encontraba Gerbner acuñó nuevos conceptos que hicieron evolucionar la teoría, pues mostraba ciertas carencias al no poderse confirmar las cifras obtenidas por ellos al reexaminar los datos con controles de las variables sociodemográficas por vía simultánea (Hirsch, 1980). Plantearon así dos nuevos conceptos: el de "resonancia" y el de "corriente principal", que se referían a aquello que presentan los medios y que también forma parte de la vida real dando así una "dosis doble" de ese contenido, y el punto de vista común o convencional al que llegaban los espectadores de gran consumo, respectivamente.

Al respecto de estos efectos, en relación a la socialización, planteados por Gerbner y generados por la televisión, cabe señalar que de forma un tanto paralela ha sido planteado por otros autores como McCombs (1994) el impacto de los telediarios sobre la visión del mundo del telespectador. Concretamente, este autor muestra cómo el contenido de las noticias tiende a influir significativamente en la vida de las personas, llegando a configurar lo que podríamos entender como "agenda social". Es decir, los telespectadores no sólo aprenden a través de ellos sobre los hechos, sobre lo que les muestra la televisión, sino sobre todo con respecto a la importancia relativa de los temas tratados. La televisión difiere de otros 
mass media por su producción masiva centralizada de un conjunto coherente de imágenes y mensajes producidos para poblaciones globales y en su relativamente poco selectiva y casi ritual utilización. Sobre todo, en relación al carácter comercial de muchos de los programas, debemos tener presente que es ésa y no otra su finalidad, por lo que en numerosas ocasiones, los patrones de televisión más frecuentes y repetitivos son comunes a todos los canales y para un espectador medio son ineludibles (Signorielli, 1986). Nos basta sólo con pensar un poco respecto a nuestra vida diaria para darnos cuenta de que incluso los telediarios adoptan para su transmisión forma de historias. Por otra parte, la entrada de los nuevos avances tecnológicos en relación a la televisión (por ejemplo, televisión por cable) podría hacernos pensar que implica una modificación de los hábitos de visionado, y que esto se traduzca en opiniones, valores y estereotipos muy diferentes a los presentes en los programas de las cadenas habituales, pero no existe evidencia de que esto sea así (Morgan, Shanahan y Harris, 1990).

A lo largo de toda su trayectoria, Gerbner plantea como esenciales dos grandes conclusiones sobre el impacto de este medio en nuestra sociedad (Gerbner et al., 1994): la televisión constituye la fuente común primordial de socialización y de información cotidiana; a través de este proceso de socialización, la televisión ejerce un efecto paulatino y acumulativo en los individuos, determinando conductas, actitudes, normas sociales, prejuicios, y hasta ideologías políticas. Sin embargo, numerosas investigaciones (Condry, 1989; O'Keefe y Reid-Nash, 1987) han ido corroborando que la incubación ${ }^{4}$ puede depender más del tipo específico de programas vistos que de la cantidad total de horas dedicadas a esta actividad. Así, Rubin y sus colaboradores (1988) concluyen que variables como la identificación del espectador con los personajes, el aislamiento social, el coeficiente de inteligencia y las necesidades informativas del televidente producen efectos diferenciados en la incubación.

Así, desde estos planteamientos se entiende que la influencia que ejerce la televisión (y los medios de comunicación en general) es a largo plazo, y no a corto plazo como tradicionalmente se ha investigado. Se considera que los efectos generados por la televisión no son inmediatos en los sujetos telespectadores, antes bien al contrario. Pues, ulos estudiosos inmersos en la investigación tradicional encuentran muy difícil aceptar el énfasis del análisis de aculturación aplicado a una inmersión total en lugar de realizar un visionado selectivo y sobre la evidencia de similitudes estables de aspecto en lugar de hacerlo sobre las demás fuentes de cambio y de diferenciación cultural" (Gerbner, Morgan y Signorielli, 1996, 39).

En relación a los procesos de aprendizaje y construcción que forman parte del proceso de cultivo, Hawkins y Pingree (1982) afirman que la televisión nos puede enseñar cosas sobre la realidad social y que la relación entre ver televisión y dicha realidad social puede ser bidireccional: ver la televisión causa una determinada

\footnotetext{
${ }^{4}$ Aculturación, cultivo.
} 
construcción de la realidad social, pero dicha construcción puede también influir en la conducta al ver la televisión. Del mismo modo, plantean que para que los efectos sean posibles el aprendizaje tiene que darse, aunque sea de forma incidental, y los factores relevantes en el aprendizaje han de entrar en juego.

Gerbner y Gross (1980) plantean que las personas que ven la televisión con bastante frecuencia tienden a ver el mundo como más inseguro y mezquino que aquellos que la ven con menor frecuencia. En líneas generales, la teoría de los efectos de cultivo mantiene que la visión del mundo de los sujetos que pasan muchas horas delante del televisor es, con toda probabilidad, la visión del mundo que presenta la televisión. Es el denominado síndrome del mundo mezquino (Signorielli y Morgan, 1990). De este modo, el medio televisivo no cultiva sólo sistemas de creencias, sino que produce también actitudes emotivas correspondientes a los sistemas de creencias. Según la teoría del cultivo, el mecanismo se activa respecto a todas las esferas de la realidad social representadas en el universo de la televisión. Por ejemplo, algunos autores han notado que los grandes consumidores de televisión manifiestan una amplia gama de estados emocionales y cognitivos que incluyen una acentuada falta de autoestima y una mayor sensibilidad hacia los problemas raciales, perciben a los ancianos como más marginales, débiles o inútiles, tienen unos niveles de ansiedad más elevados y demuestran una mayor insatisfacción respecto al propio estilo de vida (Rubin, Perse y Taylor, 1988).

Otro de los efectos que produce la televisión entre las personas que pasan largas horas delante de la pequeña pantalla es que adoptan una visión del mundo intermedia, compartida igualmente por otras personas. Por contra, quienes ven menos televisión mantienen una visión del mundo más diversa y abierta (Harris, 1994).

Una de las principales aportaciones de la teoría del cultivo es el término denominado mainstreaming, es decir, la homogeneización de las percepciones sobre la realidad social de los individuos dentro de una corriente principal. La memoria almacena todo lo que ve en televisión casi de forma automática (Shapiro, 1997). Entonces, las personas utilizan la información almacenada para formular creencias acerca del mundo real (Potter, 1988). Cuando este mundo construido y el mundo real tienen un alto grado de correlación, se da el denominado estado de resonancia o prolongación de la visión del mundo, con lo cual el efecto de la televisión es, incluso, más fuerte.

Sin embargo, resulta evidente que la investigación de cultivo ha podido estar limitada en parte por sus suposiciones sobre los contenidos televisivos y sobre la naturaleza del acto de ver televisión. En éste y otros sentidos, esta teoría también ha recibido críticas.

El fracaso relativo en confirmar los efectos de cultivo en otras culturas que no sean la norteamericana, sugiere que la hipótesis inicial del enfoque era demasiado general. El desarrollo del pensamiento referente a la construcción activa de significados por los individuos y el disminuido "poder del texto" también debilitan la suposición de un efecto acumulativo a largo plazo de los poderosos "sistemas de mensajes" (McQuail y Windahl, 1997, 129). 
Diversos estudios muestran que el control de ciertas variables sociodemográficas e individuales tienden a reducir o eliminar los efectos del cultivo (Hughes, 1980; Perse, 1986; Wober y Gunter, 1988). Otra de las críticas a los estudios del cultivo se basa, fundamentalmente, en cuestiones metodológicas. Así, se considera que existe una errónea utilización de preguntas que encierran respuestas subjetivas en algunos de los estudios realizados, además de ciertos problemas con los instrumentos de medida (Potter, 1986). Por otra parte, también ha habido críticas dirigidas a algunas de las hipótesis sobre las que se basa la teoría del cultivo. Hawkins y Pingree (1982) afirman que la teoría parece asumir, sin poder demostrarlo, que los mensajes de la televisión son esencialmente uniformes y presentan una visión única del mundo. Igualmente, tampoco se puede demostrar que los receptores aceptan inexorablemente lo que ven como la realidad percibida.

Del mismo modo, las verificaciones de las hipótesis comprobadas en contextos nacionales diferentes a los de los Estados Unidos no han ofrecido su confirmación; se puede suponer que el proceso de cultivo se pueda circunscribir a un contexto televisivo, social y cultural bien definido y no sea generalizable (Wolf, 1994). Todo ello ha conducido a los propios investigadores a replantearse algunas cuestiones y ampliar las miras de sus planteamientos. Así, Signorielli y Morgan (1990) consideran que pueden ser objeto de investigación algunas cuestiones críticas que hasta el momento no habían sido tratadas. Dichas cuestiones hacen referencia a: ¿cómo acontece al cultivo?, ¿qué sectores de la población tienen mayor probabilidad de ser afectados?, ¿que papel desempeña el cultivo en la experiencia personal?, ¿cómo influye el cultivo en las actitudes hacia el medio televisivo?, ¿qué papel desempeñan los programas específicos?, ¿cómo intervienen en el cultivo otros medios de comunicación? En palabras de Lucas et al. (1999, 234-235)

el proceso de cultivo puede quedar resumido en las siguientes etapas: 1) los espectadores observan en la televisión un mundo que difiere sustancialmente del mundo real, tanto en lo referente al contenido de los hechos como en los papeles sociales; 2) los grandes consumidores de televisión experimentan un desplazamiento de la realidad, es decir, quedan influidos en su percepción de la realidad social por los contenidos televisivos; 3 ) las representaciones sociales presentes en el universo televisivo no se absorben de manera selectiva.

Sin duda, los planteamientos de que parte esta teoría ponen el acento sobre la influencia socializadora del medio televisivo, sobre cómo el medio reitera y la audiencia recibe mensajes que reflejan la realidad social. Así, a pesar de las críticas realizadas a estos planteamientos, consideramos de gran interés para nuestro trabajo recoger estas aportaciones, pues la investigación e intervención educativa precisan de una perspectiva ecléctica y enriquecedora a la hora de abordar nuestro objeto de estudio. 


\subsection{La teoría de usos y gratificaciones}

Tal y como señalábamos anteriormente, son diversas las perspectivas que en la investigación de los medios de comunicación se han ido dando, en función de los planteamientos que se encuentran a la base de cada una de estas aportaciones. Así, en la década de 1940 comienza a trazarse, con los análisis funcionales, la línea de usos y gratificaciones, siendo los primeros estudios, básicamente, descriptivos (Wimmer y Dominick, 1996). Estos trabajos se centraron en las funciones desempeñadas por los medios, aportan un enfoque bastante diferente, en el que los investigadores ya no centran su preocupación sobre los efectos de los medios sino sobre el estudio de las necesidades de la audiencia.

En un primer momento, Lazarsfeld y Stanton (1944) estudiaron los motivos de la audiencia para oír seriales y concursos. Igualmente, cabe destacar a Lazarsfeld y Merton (1948) pues también contribuyeron a desarrollar los primeros estudios funcionales en relación a los medios. Estos autores pretendieron atribuir estatus y ética a las funciones y una difusión narcotizante a los mass media. Por otra parte, Berelson (1949) realizó un estudio acerca de lo que los lectores de los diarios neoyorquinos dijeron que echaron en falta durante una huelga de periódicos. Buscaban así las razones del atractivo evidente de los medios de difusión y de diversos tipos de contenido, preguntando a la audiencia qué pensaban, sentían y apreciaban sobre la base de su uso personal de los medios. Del mismo modo, Lasswell (1948) planteó como actividades relativas a los medios que ejercen un efecto común en la sociedad: la vigilancia del entorno, la correlación de partes del entorno y la transmisión de la herencia social. Unos años más tarde, Horton y Wohl (1956) concluyeron que el visionado de la televisión aporta a la audiencia un sentimiento de interacción parasocial con las personalidades mediáticas, mientras Pearlin (1959) argumentó que el visionado televisivo da a la sociedad la oportunidad de evadirse de las experiencias desagradables ${ }^{5}$ que a cada uno le toca vivir.

En línea con lo anteriormente expuesto, Wright (1960) afirmaba que el entretenimiento resultaba ser otra función-actividad proporcionada por los medios, a la par que planteaba la existencia no sólo de funciones sino también de disfunciones, y Mendelsohn (1963) apuntaba que dicho entretenimiento mediático reduce la ansiedad creada por los informativos emitidos por los medios. También Stephenson (1967) arguye a partir de sus trabajos de investigación que la televisión posibilita el recreo.

Sin duda, se observa cómo el foco de atención se va desplazando hacia lo que planteaba Klapper $(1963,517)$ al argumentar que la investigación de comunicación de masas estaba demasiado centrada "en la tarea de determinar si algún efecto en particular se realizaba o no", habiendo encontrado muy pocas respuestas definitivas a todas las preguntas sobre efectos. Klapper (1960) describe este periodo

\footnotetext{
5 Válvula de escape, desconexión.
} 
inicial como una "orientación funcional", que podría dar cuenta del atractivo del contenido "escapista" de los medios. Así, la audiencia llegó a ser estudiada por sí misma. Al respecto, señalan McQuail y Windahl (1997, 158), "un momento clave [...] fue la publicación de una colección de artículos bajo el título The uses of mass communication (Blumler y Katz, 1974)". De este modo, el paradigma de usos y gratificaciones, propiamente dicho, nace a partir de los trabajos de Katz, Blumer y Gurevitch (1974).

Por lo que respecta a la corriente de usos y gratificaciones propiamente dicha, Ruddock (2001) afirma que después de la Segunda Guerra Mundial ya eran evidentes las limitaciones de los estudios de efectos y se trataba de buscar nuevas maneras de estudiar la comunicación social. Así surgió la investigación de usos y gratificaciones. Se trata de una corriente con una fecha de nacimiento, unas características peculiares, unas orientaciones teórico-prácticas bien diferentes a las planteadas dentro del enfoque de efectos. Es por ello que, si bien en ocasiones, tradicionalmente, se la ha incluido en el marco del estudio de los efectos, hoy podemos afirmar la existencia de la teoría de usos y gratificaciones por sí misma (Huertas, 2002). Todos los autores coinciden en calificar esta teoría como la primera que adjudica a la audiencia la capacidad de actuar, cuestionando seriamente la relación estímulo-respuesta que alude a la pasividad de los receptores. Los estudios desarrollados desde la perspectiva de usos y gratificaciones nos presentan a unos receptores que actúan en función de sus necesidades, motivaciones e intereses, pues el uso de los medios les aporta unas gratificaciones (Cuesta, 2000). En este sentido, Klapper (1960) ya advirtió que son varios los elementos que pueden interceder entre un mensaje y su respuesta, de manera que, en la mayor parte de los casos, los mensajes mediáticos pensados para persuadir refuerzan de hecho las actitudes ya existentes. En este sentido, y a partir de estos factores influyentes, se puede argumentar que "los mass media por sí solos no son normalmente causa necesaria ni suficiente de efectos de audiencia, y el medio de un mensaje significa solamente una fuente de influencia en los entornos sociales y psicológicos" (Rubin, 1996, 556). Sin duda, los trabajos desarrollados en el marco de esta corriente de investigación recogen entre sus conclusiones más importantes que la audiencia es activa y que el uso que se hace de los medios está muy relacionado con las expectativas y necesidades de los espectadores (Vilches, 1999).

Por otra parte, la complejidad de los fenómenos sociales obliga a no trabajar en términos de causa-efecto. Así, la teoría de usos y gratificaciones adopta una perspectiva a través de la que se desplaza el interés de la investigación del mecanismo en los efectos directos de los mass media sobre los receptores, para llegar a conocer qué uso hace la sociedad de dichos medios, "qué intenciones o funciones sirven los media dentro de un corpus de receptores activos [...] tal y como los controlan los propios patrones de elección de los receptores" (Fisher, 1978, 159). De este modo se subrayan tanto el uso como la elección individuales. Es decir, se trata de indagar en qué es lo que la gente hace con los medios (Klapper, 1963). Desde los usos y gratificaciones se ha tratado de buscar explicaciones teóricas sobre 
aquellas cuestiones que se estudiaban de forma empírica, manteniéndose esta tendencia vigente en la trayectoria de dicha corriente. Tal y como plantea Huertas $(2002,53)$ "todas las investigaciones sobre la audiencia de medios tienen un objetivo común: incrementar el conocimiento de cómo los distintos grupos sociales, en el marco de la sociedad y la cultura, usan los medios y, en consecuencia, cómo los medios pueden ser vehículos de estabilidad y/o cambio social". Es decir, se plantea desde aquí que algunas necesidades, combinadas con características personales de los sujetos y su entorno social, producen una determinada percepción de los problemas y de las soluciones a los mismos, tal y como afirma Rosengren (1974). Analiza la interacción entre lọs medios y la audiencia (Rayburn, 1996), teniendo en cuenta las necesidades de los individuos, sus motivos para la comunicación, el entorno psicológico y social, la conducta comunicativa y las alternativas funcionales al uso de los medios. Así, las gratificaciones corroboradas por la audiencia pueden deberse al contenido, a la práctica de exposición en sí misma o a la situación social en que se da (Rosengren, Wenner y Palmgreen, 1985). El público efectúa su propia selección, elección y uso para gratificar sus necesidades, en vez de dejarse utilizar por los mass media (Katz, Gurevitch y Haas, 1973).

En palabras de Katz, Blumler y Gurevitch $(1974,20)$, los objetivos de esta corriente se centran en buscar "(1) los orígenes sociales y psicológicos de (2) las necesidades que generan (3) expectativas de (4) los medios de comunicación o de otras fuentes, que llevan a (5) diferentes patrones de exposición a los medios (o compromiso con otras actividades), resultando la (6) necesidad de gratificaciones y (7) otras consecuencias, quizá la mayoría sin proponérselo». Rubin (1996) resume estos planteamientos iniciales en tres objetivos principales: explicar cómo los individuos utilizan los medios para gratificar sus necesidades; entender los motivos que rigen la conducta mediática; identificar las funciones y consecuencias que se dan y que están vinculadas a las necesidades, motivos y comportamientos mediáticos. Así, esta teoría asume que las personas podemos articular nuestros propios motivos para exponernos a los medios y a determinados contenidos. Así, a nivel metodológico, desde la perspectiva de usos y gratificaciones se ha tratado de analizar cuáles son los motivos por los que la audiencia se expone a los medios e inferir así las gratificaciones que comporta la utilización de los medios.

En este sentido, tal y como plantea Rubin (1996), inicialmente la investigación centrada en usos y gratificaciones trataba de buscar las razones por las que las personas consumían cierto tipo de contenido mediático. Así, Herzog (1944) estableció tres tipos de "gratificación" en relación al seguimiento de las telenovelas radiofónicas de la época: descarga emocional, ensoñación y búsqueda de consejo. También Lazarsfeld (1940) estudió y describió los motivos de la audiencia para sentirse atraída por los programas de radio. Del mismo modo, Berelson (1949) preguntó a la gente por qué leía el periódico y agrupó las respuestas en cinco modalidades: búsqueda de información, de prestigio social, de escapismo, como elemento de utilidad para la vida diaria y como componente de un contexto social. En un mismo orden de cosas, los estudios se orientaron hacia el conocimiento del uso que hacía 
la audiencia de la televisión y de las gratificaciones que ésta les aportaba. Se apuntaba que "la televisión es, esencialmente, un medio de entretenimiento familiar; sobre la prensa se destacó que la utilización de ésta es de carácter informativo e individual y, por último, se destacó que el uso de la radio es más individual y se suele emplear como compañía y modo de entretenimiento" (Huertas, 2002, 106).

Sin duda, el auge de esta corriente comienza a producirse a partir de los años 50 , centrándose los estudios en la relación de los niños con los medios, intentando investigar sobre el modo en que les influyen, junto con el contexto familiar, escolar y las amistades. Los avances de esta teoría llevaron, durante los años cincuenta y sesenta, a atender a las variables personales, sociológicas y psicológicas, que podrían ser explicativas de los distintos patrones de consumo y obtención de satisfacción. Así, varios autores (S’hramm, Lyle y Parker, 1961) detectaron que los niños están condicionados en sus hábitos televisivos por su habilidad intelectual individual y el tipo de relación experimentado con sus padres y compañeros de clase o juegos, entre otros factores. Del mismo modo, se detectó que el factor racial era importante a la hora de predecir el uso de los medios (Gerson, 1966), al igual que la clase social como factor que predeterminaba el modo en que utilizaban la televisión como fuente informal de aprendizaje (Greenberg y Dominick, 1969).

Por otra parte, se plantea en estos años que la mayor parte del uso que se hace de los medios es con la finalidad de escapar de la realidad (Katz y Foulkes, 1962). Así, en la década de los 60 se sucedieron una serie de investigaciones y teorizaciones de gran importancia, que demostraron la posibilidad de aplicar paradigmas funcionales al análisis de la conducta frente a los mass media. A título de ejemplo encontramos en esta línea la teoría de Stephenson (1967), quien aplicó el concepto de juego, situándolo a la base del uso que la mayoría de los individuos hacen de los medios.

Tal y como plantean Katz, Gurevitch y Haas (1973), a comienzos de los años 70 se da una importante renovación de los estudios empíricos y los investigadores trataban de estudiar la motivación de la audiencia, llegando a elaborar una serie de tipologías en relación a la utilización de los medios para gratificar las necesidades, tanto psicológicas como sociales, de la audiencia. McQuail, Blumler y Brown (1972) construyeron una tipología que respondía a las gratificaciones obtenidas por la audiencia al consumir televisión, llegando a concluir que las personas se sienten motivadas hacia el consumo de televisión, principalmente, por: diversión, relaciones personales, identidad personal y vigilancia. Sin embargo, desde las aportaciones de otros autores se plantea que las posibilidades que ofrece el entorno ante las necesidades de las personas pueden resultar tanto satisfactorias como insatisfactorias (es lo que ellos denominan "grado de dependencia") y es por ello que los sujetos pueden hacer uso de otras alternativas para complementar o sustituir el consumo de los medios (Rosengren y Windahl, 1972). Del mismo modo, plantean que la necesidad de interacción e identificación puede dar lugar a cuatro tipos de vinculación con los medios: distanciamiento, interacción parasocial, identificación solitaria o captura. Igualmente, el grado de proximidad a la realidad que tenga el 
contenido de los medios (desde contenido ficticio no informativo hasta contenido informativo no ficticio) resulta ser una clave a la hora de analizar la necesidad de interacción de la audiencia con dichos medios.

Por otra parte, Katz, Gurevitch y Haas (1973) elaboraron una tipología relativa al uso de los medios por parte de la audiencia para satisfacer necesidades relevantes para sus vidas. Dicha tipología recogía: el refuerzo de la comprensión hacia uno mismo, de la comprensión de los amigos, de otras personas o de la sociedad en general; el refuerzo del estatus personal o del de la sociedad y el refuerzo del contacto con la familia, iguales, la sociedad o la cultura a la que pertenecían. Por otro lado, no podemos olvidar la aportación que supuso para los usos y gratificaciones el paradigma que aportó Rosengren (1974). Desde dicha aportación se plantea que las necesidades de los individuos constituyen el punto de partida (haciendo referencia a la jerarquía de las necesidades humanas, de acuerdo con Maslow), pero para que éstas lleven a una acción relevante, tienen que ser percibidas como problemas, y tiene que percibirse alguna solución potencial. En su modelo afirma que la experiencia de las necesidades es moldeada o influida por aspectos de la estructura social (nivel de desarrollo, tipo de sistema político), y también por características individuales (por ejemplo, la personalidad, la posición social, la situación en el ciclo vital). Así, la percepción de los problemas y de las soluciones potenciales lleva a la formulación de los motivos para el uso de los medios o para otros tipos de conducta.

Cabe destacar la aportación realizada desde planteamientos que apuntan a que no es apropiado utilizar la misma teoría y el mismo modelo de usos y gratificaciones de la audiencia para todos los tipos de contenidos informativos o de usos de los mass media (McQuail, 1984). Dentro de la teoría de usos y gratificaciones, la principal corriente de investigación es esencialmente utilitarista, y supone una relación lógica entre los medios (uso de los medios) y los fines (gratificaciones). Además, puede ajustarse a muchos usos informativos de los medios, pero no parece que encaje con las circunstancias que con más frecuencia se dan en el uso recreativo e imaginativo de los medios. Es por esto que se ha llegado a plantear la necesidad de un modelo "culturalista", pues se considera que la experiencia de los individuos con los medios es, sobre todo, cultural y hemos de prestar atención al contenido de tipo afectivo e imaginativo y, también, a los usos que siguen una pauta más "ritual" que instrumental. "El gusto cultural personal guía las preferencias y las elecciones sobre el contenido de los medios (por géneros, formatos o tipos de contenido concretos) y conduce a varios tipos de satisfacciones afectivas o emocionales" (McQuail y Windahl, 1997, 164). Se ha evidenciado desde esta perspectiva que algunos sujetos incluso ven programas que de verdad les disgustan sobremanera simplemente para tener algún tema de conversación y sentirse menos solos (Palmgreen, 1984). Esto también queda reflejado en la clasificación que realiza Winick (1988), quien habla de seis funciones de la televisión, enumerándolas según su importancia: 1) información; 2) relax y entretenimiento; 3) conversación; 4) motivos sociales; 5) estar al día; 6) compañía. 
Como puede observarse, tanto las aportaciones teóricas como los resultados de las investigaciones relativos a los usos que se destacan, por parte de diferentes autores, hacen referencia al placer obtenido por los sujetos. De ahí el nombre de esta corriente, así como el hecho de que muchos investigadores la consideren la primera que habla de los medios como algo benigno (Langer, 2000). Incluso hay autores que afirman que los individuos que tienen sentimientos desagradables o poco placenteros buscan escapar de los mismos mediante la televisión (Kubey, 1992). Parece cierto, pues, que la televisión cubre unas necesidades de las personas y que hoy en día no se entiende la vida sin, al menos, una televisión. En este sentido, cabe destacar aquí la aportación de Winick (1988) mediante la realización de dos estudios. En ellos se les pagaba a las familias por no ver la televisión. Una vez finalizados, se demostró que las familias estudiadas no podían estar sin hacer uso de la televisión. Sin embargo, también fue interesante observar cómo las familias cambiaron sus conductas respecto al uso de los otros medios de comunicación, comprando más el periódico, recurriendo a la radio como fuente de entretenimiento. Del mismo modo, realizaron más actividades sociales (pasear, visitar amistades, etc.).

En definitiva, todos estos estudios caminaban hacia la sustitución de la perspectiva tradicional en la investigación de los efectos producidos por los medios, por una perspectiva funcionalista. Una diferencia entre los investigadores tradicionales de los efectos de los medios y los investigadores de la perspectiva de los usos $y$ gratificaciones consiste en que los primeros tienden a examinar la comunicación de masas desde la perspectiva del emisor, mientras que en el caso de los usos y gratificaciones, el punto de partida se centra en la audiencia (Windahl, 1981). Este mismo autor, junto a su colega Rosengren (Rosengren y Windahl, 1972, 176), plantea la necesidad de llegar a una fusión, de reunificar ambas perspectivas y de "preguntarse qué efecto produce un uso determinado de los mass media o qué efecto una gratificación determinada obtenida a través de los media".

En este sentido, un gran número de las investigaciones sobre la televisión se han centrado, principalmente, en los efectos de la misma y mucho menos en la atracción de o hacia la televisión. De hecho, existen estudios en los que se demuestra que la atracción hacia determinados programas incrementa las posibilidades de que éstos produzcan efectos en sus receptores (Conway y Rubin, 1991). Sin duda, se hace cada vez más evidente la necesidad de adoptar una postura ecléctica donde tengan cabida todos estos planteamientos. Una aportación significativa por parte de Windahl (1981) ha sido el planteamiento del término "consefectos" del contenido de los medios, utilizado para designar las observaciones que en parte derivan del propio contenido consumido (una perspectiva habitual en el estudio de los efectos) y en parte del modo de usar el contenido (la perspectiva típica de la escuela de los usos y gratificaciones)" (Wimmer y Dominick, 1996, 368). De este modo, se puede establecer una conexión entre el enfoque clásico y tradicional con esta otra línea más funcionalista, al tener en cuenta en la interpretación de los datos 
la relación entre los motivos que tiene y ofrece la audiencia, las satisfacciones que le aportan los medios y las consecuencias.

Sin embargo, las contribuciones que se han ido realizando desde el paradigma de usos y gratificaciones no han estado exentas de críticas por parte de otros autores, aunque no podemos olvidar que la mayoría de dichas detracciones hacen referencia a los primeros estudios desarrollados desde esta perspectiva. Las principales críticas, tal y como plantea Rubin (1996), podrían sintetizarse en cinco: 1) Para algunos autores (Carey y Kreiling, 1974; Elliot, 1974), las aportaciones desde los usos y gratificaciones son excesivamente individualistas, ya que se centran en el consumo por parte de los sujetos que integran la audiencia, dificultando así la explicación generalista más allá de la población estudiada. Si bien cabe aquí señalar que también ha sido valorado el hecho de indagar desde este paradigma en cómo los usos y efectos mediáticos afectan a personas distintas (Dader, 1992; Rubin, 1996); 2) Hay autores que critican el hecho de que los estudios se han fragmentado y han dado como resultado una serie de tipologías separadas (Anderson y Meyer, 1975; Swanson, 1979); 3) Por lo que se refiere a los términos utilizados desde este paradigma, algunos críticos (Anderson y Meyer, 1975; Blumler, 1979; Elliot, 1974; Dader, 1992) han señalado la falta de claridad sobre todo en los conceptos centrales como "necesidades", "motivos", "conducta", "fondo social y psicológico" y "consecuencias"; 4) Hay autores que consideran que los estudiosos de los usos y gratificaciones acuerdan significados diferentes para conceptos como "motivos", "usos", "gratificaciones" y "alternativas funcionales" (Elliot, 1974; Swanson, $1977,1979)$; 5) Por último, han sido criticadas tanto la consideración de la audiencia activa como la utilización de datos de autoinforme (Elliot, 1974; Swanson, 1977, 1979), ya que en ocasiones la actividad ha sido tratada como variable y no como una descripción de la audiencia, al tiempo que la interpretación de los autoinformes ha estado, probablemente, poco cuidada.

En línea con lo anteriormente expuesto, Palmgreen (1984) plantea, ante la evidencia de estar surgiendo una estructura teórica más compleja, la necesidad de un modelo que integre el análisis multivariable. Sin duda, el núcleo de dicho modelo lo constituye el concepto de búsqueda de satisfacciones por parte de la audiencia. Sin embargo, señala la importancia de las variables antecedentes que actúan sobre dicho concepto como la estructura de los medios, la tecnología que emplean, el entorno social, las características psicológicas de los usuarios, sus necesidades, valores y creencias. Evidentemente, cabe valorar este modelo como un paso adelante en la comprensión del proceso mediático, aunque se enriquecerá con aportaciones por parte de otros autores, con planteamientos diferentes aunque con la misma base.

Sin embargo, no podemos dejar de hacer referencia aquí al estudio de "lo afectivo" por parte de diferentes autores del paradigma de usos y gratificaciones, ya que en la evolución de dicho paradigma ha ido cobrando cada vez mayor importancia. En numerosas ocasiones se observa cómo las necesidades de interacción y emotividad no quedan cubiertas en la sociedad contemporánea y se buscan en el 
consumo televisivo. Así, Rubin, Perse y Taylor (1988) plantean que los grandes consumidores de televisión manifiestan una amplia gama de estados emocionales y cognitivos provocados por la falta de autoestima. Por otra parte, Maffesoli (1990) afirma que la racionalización social, determinada por papeles sociales rígidos, está perdiendo vigencia en beneficio de la sociabilidad y la dominación empáticas. Las personas se agrupan por reconocerse empáticamente, por tener intereses en común, y esto también lo encuentra en los personajes mediáticos. Ahora bien, merece aquí una mención concreta Calbo (1998), quien desde un planteamiento mucho más actual y de forma empírica abordó esta cuestión. En su trabajo siguió una metodología cualitativa, que más tarde le llevó a una serie de reflexiones teóricas que resultan de gran interés desde nuestro punto de vista. Él plantea que la relación con el medio viene condicionada por la posición que la persona ocupa en la sociedad y la propia naturaleza del espacio televisivo. Y todo ello bajo el prisma de que no se da una respuesta emocional a un estímulo, sino que ésta es más bien el resultado de una acción totalmente consciente.

Desde un planteamiento más actual, Pérez de Silva (2000) también afirma que la nueva televisión se convierte en sentimiento. Al permitir una personalización del producto audiovisual, se crea una experiencia de entretenimiento única para cada telespectador. Junto a esto, cabe señalar la existencia de algunas propuestas para llevar a cabo una investigación que reúna usos y gratificaciones y efectos mediáticos (Rosengren y Windahl, 1972; Rubin y Windahl, 1986; Windahl, 1981). Incluso, podemos afirmar que la principal crítica realizada al paradigma de usos y gratificaciones ha sido la ausencia de atención a los efectos. Precisamente, a través de los planteamientos de usos y efectos se ha tratado de superar las limitaciones de que adolecía dicho paradigma. No podemos olvidar que, a priori, existe una importante diferencia entre ambas perspectivas: la investigación de efectos está orientada, fundamentalmente, a la comunicación de masas desde la postura del comunicador, mientras que el investigador de usos y gratificaciones toma como punto de partida a la propia audiencia (Windahl, 1981). Aunque, por otra parte, cabe señalar como aspecto en común que ambas perspectivas tratan de explicar las consecuencias de la comunicación de masas. Como aspectos diferenciadores a destacar de los usos y gratificaciones hay dos ideas básicas que subyacen a los planteamientos de este paradigma y que debemos tener presentes para poder comprender la complejidad de un enfoque que recoja usos y efectos. La primera, referida a la actividad de la audiencia; la segunda, dirigida al estudio de la dependencia que se genera en la misma respecto de los medios. Todo ello sin olvidar la gran importancia que encierran las características psicosociales de los sujetos con quienes se trabaja desde esta perspectiva.

Una evolución reciente de la teoría de usos y gratificaciones consiste en la integración de estas dos áreas: usos y efectos (Rubin, 2002). Esta nueva perspectiva (usos-efectos) pretende explicar los efectos producidos, no sólo a partir del nivel de exposición, sino teniendo en cuenta los factores que explican el consumo mediático (como los motivos de exposición). Desde estos planteamientos se 
postula que los efectos y la recepción mediática dependen de la interacción entre las características de los contenidos y las características de la audiencia.

3. DiSCUSIÓN Y REFLEXIÓN PEDAGÓGICA: HACIA UNA PERSPECTIVA TEÓRICA ECLÉCTICA PARA EL ESTUDIO DE LA INFLUENCIA DE LA TELEVISIÓN

El análisis realizado en este trabajo nos conduce, necesariamente, a la reflexión pedagógica respecto a la importancia de abordar la influencia del medio televisivo en el proceso de socialización a partir de distintas perspectivas teóricas. Sin duda, se hace necesaria la adopción de una perspectiva extensa en que tengan cabida aportaciones tan diversas como complementarias.

Indudablemente, tomar en consideración estos tres modelos de análisis responde a la evidencia de su estrecha relación con las investigaciones sobre los procesos de socialización, si bien presentan, a nuestro juicio, carencias que deben ser superadas. En este sentido, se hace necesario superar los planteamientos extremos y unívocos esgrimidos desde posturas enfrentadas para llegar al enriquecimiento del estudio de la realidad que nos ha tocado vivir.

Así, partir de la actividad de la audiencia (tal y como se afirma desde la perspectiva de usos y gratificaciones) para profundizar en el estudio de la influencia del medio televisivo y conocer así los efectos generados en la misma resulta de gran relevancia. Pero, con ello no pretendemos negar las contribuciones realizadas a partir de las otras perspectivas analizadas, antes bien al contrario, pues esto nos ayuda a una mejor y mayor comprensión del fenómeno objeto de nuestro estudio.

En este sentido, nuestra reflexión se orienta a la evidencia de que cada una de las teorías revisadas parte de principios bien diferenciados y no dejan cabida al enriquecimiento de las aportaciones del resto sino que adoptan perspectivas dirigidas, únicamente, a la demostración de sus planteamientos. Ante esto, nuestro propósito es incidir en la posibilidad y necesidad de integrar y ampliar los diferentes supuestos, pues todos ellos alimentan el mismo objeto de conocimiento aunque desde perspectivas diferenciadas.

Sin duda, cabe reflexionar aquí sobre las carencias más importantes que, a nuestro juicio, muestra cada uno de los modelos analizados. Así, la primera perspectiva revisada (teoría del aprendizaje social) deja de considerar, entre los factores personales a los que hace referencia, el ámbito afectivo del sujeto, cuestión que consideramos imprescindible si se desea conocer cómo, por qué y en qué medida los televidentes son influenciados por el medio televisivo. Del mismo modo, cabe señalar la necesidad de que la teoría de cultivo tome en consideración las diferencias entre individuos a la hora de procesar la información, la construcción activa de significados por parte de los individuos, restando así "poder" al texto y a la imagen. Junto a éstas, la teoría de usos y gratificaciones, si bien orienta sus postulados en una dirección bien diferente pues parte de la actividad e implicación de la audiencia en el proceso de adquisición y elaboración de la información recibida, 
deja a un lado la consideración del contenido mediático que se ofrece, pues la elección que realizan las personas está en buena medida influenciada por el contenido ofertado.

Desde nuestra perspectiva, como clave para el avance en el estudio y comprensión de la influencia del medio televisivo, se hace necesaria la superación de aquellas limitaciones (vigentes en la actualidad) que responden a la insistencia en centrarse, prioritariamente, en el medio televisivo y sus características, tal y como se plantea desde la teoria de usos y gratificaciones (desde donde incide en la necesidad de tomar a la audiencia como protagonista del proceso). En la misma línea, consideramos necesario integrar estos planteamientos con las aportaciones realizadas desde otros enfoques significativos como los socioculturales pues aportan una nueva manera de observar la recepción televisiva, reflejando una notable preocupación por la educación y por la realidad cultural e individual que cada telespectador vive. Todo ello con el propósito de complementar, ampliar y enriquecer nuestra labor.

En síntesis, conocer y comprender la influencia de la televisión en el proceso de socialización del ser humano (especialmente en relación a la infancia), constituye una ardua tarea a la par que necesaria. Para ello, desde el ámbito de la teoría de la educación, hemos de considerar distintas aportaciones que complementan y enriquecen el estudio de dicho fenómeno, posibilitan profundizar no sólo en los efectos generados en la audiencia sino, también, en cómo ésta hace uso del medio. Los efectos y la recepción mediática no dependen, exclusivamente, de las características de los contenidos sino también de las características de la audiencia.

\section{BiBLIOGRAFÍA}

Abercrombie, N. y Longhurst, B. (1998) Audiences. Londres, Sage.

Ball-Rokeach, S. J. (1972) The legitimation of violence, en Short, J. F. y Wolfang, M. E. (eds.). Collective violence. Chicago, Aldine-Atherton, 100-111.

Ball-Rokeach, S. y Defleur, M. (1976) A dependency model of mass media effects, Communication Research, 3, 3-21.

BAndura, A. (1977) Social Learning theory. NJ, Englewood Cliffs.

- (1982) The psychology of chance encounters and life paths, American Psychologist, 37, 747-755.

- (1983) Psychological Mechanisms of Aggression, en Geen, R. y Donnerstein, E. (eds.). Aggression. Theoretical and Empirical Reviews. New York, Academic Press, 11-40.

- (1986) Social foundations of thought and action: A social cognitive theory. NJ, PrenticeHall.

- (1989) Self-regulation of motivation and action through internal standards and goal systems, en PERVIN, L. A. (ed.). Goal concepts in personality and social psychology. NJ, Lawrence Erlbaum Associates, 19-85.

- (1990) Mechanisms of moral disengagement, en ReICH, W. (ed.). Origins of terrorism: Psychologies, ideologies, states of mind. Cambridge, Cambridge University Press, 162-191. 
PIEDAD MARÍA SAHUQUILLO MATEO

ALGUNAS APORTACIONES TEÓRICAS A LA INFLUENCIA

DE LA TELEVISIÓN EN EL PROCESO DE SOCIALIZACIÓN DE LA INFANCIA

- (1991) Social cognitive theory of moral thought and action, en KuRTines, W. M. y GerWIRTZ, J. L. (eds.). Handbook of moral behavior and development. NJ, Lawrence Erlbaum Associates, 45-103.

- (1994) Social Cognition Theory of Mass Communication, en BRYANT, J. y Zillman, D. (eds.). Media Effects. New Jersey, Lawrence Erlbaum Associates, 89-126.

- (1996) Teoría Social de la comunicación de masas, en Bryant, J. y Zillman, D. (eds.). Los efectos de los medios de comunicación. Investigaciones y teorías. Barcelona, Paidós Comunicación, 89-126.

- (1997) Behavioral Theory and the Models of Man, en Notrerman, J. (ed.). The Evolution of Psychology. Fifty Years of the American Psychologist. Washington, American Psychological Association, 154-172.

Bandura, A.; Underwood, B. y Fromson, M. E. (1975) Disinhibition of aggression through diffusion of responsibility and dehumanization of victims, Journal of Research in Personality, 9, 253-269.

Bereison, B. (1949) What missing the newspaper means, en LAZARSFELD, P. F. y Stanton, F. N. (eds.). Communications research 1948-1949. Nueva York, Harper, 111-128.

Berger, P. y BERGER, B. (1979) Sociology: A biographical approach. London, Penguin Books. Blumler, J. G. (1979) The role of theory in uses and gratifications studies, Communication Research, 6, 9-36.

Blumler, J. G. y KaTz, E. (1974) The uses of Mass Communications: Current perspectives on gratifications research. Beverly Hills, Sage.

Butrkel-Rothfuss, N. L. y MaYes, S. (1981) Soap opera viewing: The cultivation effect, Journal of Communication, 31, 108-115.

CALBO, S. (1998) Réception télévisuelle et affectivité. Une étude ethnographique sur la réception de programmes sériels. París, L'Harmattan.

Carey, J. W. y Kreiling, A. L. (1974) Popular culture and uses and gratifications: Notes toward an accommodation, en Buumler, J. G. y KaTz, E. (eds.). The uses of mass communications: Current perspectives on gratifications research. Beverly Hills, CA, Sage, 225-248.

Chaffee, S. H. (1982) Mass media and interpersonal channels: Competitive, convergent or complementary?, en GUMPERT, G. y CATHCART, R. (eds.). Inter/Media: Interpersonal communication in a media world. Nueva York, Oxford University Press, 57-77.

Condry, J. (1989) The psychology of television. Hillsdales, NJ, Lawrence Erlbaum.

Cuesta, U. (2000) Psicología social de la comunicación. Madrid, Cátedra.

DADER, J. L. (1992) El periodista en el espacio público. Madrid, Tecnos.

Defleur, M. L. (1967) The relative contribution of television as a learning source for children's occupational knowledge, American Sociological Review, 32, 777-789.

DurKheim, E. (1976) La educación como socialización. Salamanca, Sígueme.

Elías, N. (1990) La società degli individui. Bologna, Il Mulino.

ELLIOT, P. (1974) Uses and gratifications research: A critique and a sociological alternative, en ButmlER, J. G. y KaTz, E. (eds.). The uses of mass communications: Current perspectives on gratifications research. Beverly Hills, CA, Sage, 249-268.

EscámeZ, J. y OrtegA, P. (1986) La enseñanza de actitudes y valores. Valencia, Nau Llibres.

FIsHeR, B. A. (1978) Perspectives on buman communication. Nueva York, MacMillan.

Gerbner, G. y Gross, L. (1980) The violent face of television ands its lessons, en Paimer, E. L. y DORR, A. (eds.). Children and the Faces of Television: teaching, violence, selling. New York, Academic Press, 149-162. 
Gerbner, G.; Gross, L.; Jackson-Beeck, M.; JefFries-Fox, S. y Signorieldi, N. (1978) Cultural indicators: Violence profile, Journal of Communication, 28, 176-207.

Gerbner, G.; Gross, L.; Morgan, M. y Signorieldi, N. (1994) Growing up with television: The Cultivation Perspective, en Bryant, J. y ZILlman, D. (eds.). Media Effects. Advances in theory and research. New Jersey, Lawrence Erlbaum Associates, 17-41.

Gerbner, G.; Gross, L., Morgan, M.; Signorieldi, N. y Jackson-Beek, M. (1979) The demonstration of power: violence profile $\mathrm{n}^{\circ}$ 10, Journal of Communication, 29 (3), 177-196.

Gerson, G.; Morgan, M. y Signorielli, N. (1996) Crecer con la televisión: perspectiva de aculturación, en BRYANT, J. y Zillman, D. (1996) Los efectos de los medios de comunicación. Investigaciones y teorías. Barcelona, Paidós Comunicación, 35-66.

GERSON, W. (1966) Mass media socialization behavior: Negro-white differences, Social Forces, $45,40-50$.

GIDDENs, A. (1995) Sociologia. Madrid, Alianza.

Goranson, R. E. (1970) Media violence and aggressive behavior. A review of experimental research, en BERKOwITZ, L. (ed.). Advances in experimental social psychology. Nueva York, Academic Press, 1-31.

GreEnBERG, B. y Dominick, J. (1969) Racial and social class differences in teenager's use of television, Journal of Broadcasting, 13, 331-344.

Gross, K. y Morgan, M. (1985) Television and enculturation, en Dominick, J. y FleTcher, J. Broadcasting Research Methods. Boston, Allyn \& Bacon, 221-234.

HarRIs, R. J. (1994) A cognitive Psychology of Mass Communication. Hillsdale, NJ, Lawrence Erlbaum Associates.

Hawkins, R. P. y Pingree, S. (1982) Television's influence on social reality, en Peart, D.; BoutHILET, L. y LAZAR, J. (eds.). Television and behavior: Ten years of scientific progress and implications for the eighties. Rockville, National Institute of Mental Health, 224-247.

Herzog, H. (1944) What do we really know about daytime serial listeners?, en LAZARSFELD, P. F. y Stanton, F. N. (eds.). Radio research 1942-1943. Nueva Cork, Duell, 3-33.

HiRsCH, P. (1980) The "Scary world" of the nonviewer and other anomalies, Communication Research, 7, 403-456.

Hoffmann, L.; Paris, S. y MAY, E. (1995) Psicología del desarrollo boy. Madrid, McGraw-Hill. HORTON, D. y WOHL, R. R. (1956) Mass communication and parasocial interaction, Psychiatry, 19, 215-229.

Huertas, A. (2002) La audiencia investigada. Barcelona, Gedisa.

HUESMANN, L. R.; LAGERSPETZ, K. y ERON, L. D. (1984) Intervening variables in the TV violenceaggression relation: evidence from two countries, Developmental Psychology, 20, 746-775.

Hughes, M. (1980) The fruits of cultivation analysis: A re-examination of television in fear of victimization, alienation and approval of violence, Public Opinion Quarterly, 44, 287-302.

Jefrres, L. W. (1986) Mass Media process and effects. New York, Waveland Press.

Katz, E.; Blumier, J. G. y GuRevitch, M. (1974) Utilization of mass communication by the individual, en Blumler, J. G. y KaTZ, E. (eds.). The uses of mass communications: Current perspectives on gratifications research. Beverly Hills, Sage, 19-32.

KaTz, E. y FoulKes, D. (1962) On the use of mass media as "escape", Public Opinion Quarterly, 26, 377-388.

Katz, E.; GureVITCH, M. y HaAs, H. (1973) On the use of the mass media for important things, American Sociological Review, 38, 164-181.

KLAPPER, J. T. (1960) The effects of mass communications. Nueva York, Free Press. 
- (1963) Mass Communication research: an old road resurveyed, Public Opinion Quarterly, 27, 515-527.

Kubey, R. (1992) A critique of no sense of place and the homogeneization theory of Joshua Meyrowitz, Communication Theory, 2, 259-271.

LANG, A. et al. (1993) The effects of related and unrelated curts on television viewer's attention, processing capacity and memory, Communication Research, 20, 4-29.

LANGER, J. (2000) La televisión sensacionalista. El periodismo popular y las "otras noticias". Barcelona, Paidós.

LASSWELL, H. D. (1948) The structure and function of communication in society, en BRYSON, L. (ed.). The communication of ideas. Nueva York, Harper, 37-51.

LaZARSFeld, P. F. (1940) Radio and the printed page. Nueva York, Duell, Sloan y Pearce.

LAZARSFELD, P. F. y MERTON, R. K. (1948) Mass communication, popular taste and organized social action, en Bryson, L. (ed.). The communication of ideas. Nueva York, Harper, 95-118.

Lazarsfeld, P. F. y Stanton, F. N. (1944) Radio research 1942-1943. Nueva York, Duell.

Linz, D.; Donnerstein, D. y Penrod, S. (1984) The effects of multiple exposure to film violence against women, Journal of Communication, 34, 130-147.

Lucas, A.; García, C. y Ruiz, J. A. (1999) Sociología de la Comunicación. Madrid, Trotta.

MafFesoli, M. (1990) El tiempo de las tribus. Barcelona, Icaria.

McComBs, M. (1994) News Influence on our pictures of the World, en BRYANT, J. y ZILLMAN, D. (eds.). Media Effects. Advances in theory and research. New Jersey, Lawrence Erlbaum Associates, 1-16.

McCombs, M. E. y SHaw, D. L. (1972) The agenda-setting function of mass media, Public Opinion Quarterly, 36, 176-187.

MCQuaIL, D. (1984) With the benefit of insight: reflections on uses and gratifications research, Critical Studies in Mass Communication, 1 (2), 177-193.

McQuail, D.; Blumler, J. G. y Brown, J. R. (1972) The television audience: A revised perspective, en McQuaIL, D. (ed). Sociology of mass communications. Penguin, Middlesex, $135-165$.

MCQUAIL, D. y WINDAHL, S. (1997) Modelos para el estudio de la comunicación colectiva. Navarra, EUNSA.

MEICHENBAUM, D. (1984) Teaching thinking: A cognitive-behavioral perspective, en GLaSER, R.; Chipman, S. y Segal, J. (eds.). Research and Open Questions. Thinking and learning skills. NJ, Lawrence Erlbaum Associates, 407-426.

Mendeisorn, H. (1963) Socio-psychological perspectives on the mass media and public anxiety, Journalism Quarterly, 40, 511-516.

MEYER, T. P. (1972) Effects of viewing justified and unjustified real film violence on aggressive behavior, Journal of Personality and Social Psychology, 23, 21-29.

Milgram, S. (1974) Obedience to authority: An experimental view. Nueva Cork, Harper y Row.

Morgan, M; SHANAHAN, J. y HarRIS, C. (1990) VCRs and the effects of television: New diversity or more of the same?, en DoBrow, J. (ed.). Social and cultural aspects of VCR use. NJ, Lawrence Erlbaum Associates, 107-123.

O'KeEFe, G. J. y ReID-NASH, K. (1987) Crime news and real world blues, Communication Research, 14, 147-163.

Palacios, J.; MARChesi, A. y Coll, C. (1995) Desarrollo Psicológico y Educación. Psicología evolutiva. Madrid, Alianza Psicología.

PALMGREEN, P. (1984) Uses and gratifications: A theoretical perspective, Communication Yearbook, 8, 20-55. 
Pearin, L. I. (1959) Social and personal stress and escape television viewing, Public Opinion Quarterly, 23, 255-259.

PÉREZ DE SILVA, J. (2000) La televisión ha muerto. La nueva producción audiovisual en la era de Internet: la tercera revolución industrial. Barcelona, Gedisa.

PERSE, E. M. (1986) Soap opera viewing patterns of college students and cultivation, Journal of Broadcasting \& Electronic Media, 30, 175-193.

PotTer, W. J. (1986) Perceived reality and the cultivation hypothesis, Journal of Broadcasting E Electronic Media, 30, 159-174.

- (1988) Perceived Reality in Television Effects Research, Journal of Broadcasting and Electronic Media, 32, 23-41.

Rayburn, J. D. (1996) Uses and gratifications, en SALWEN, M. B. y STACKs, D. W. (eds.). An integrated approach to communication theory and research. Mahwah, NJ, Lawrence Erlbaum Associates, 145-163.

Ritzer, G. (1996) Teoría sociológica contemporánea. Madrid, McGraw-Hill.

ROCHER, G. (1985) Introducción a la sociología general. Barcelona, Herder.

ROSENGREN, K. E. (1974) Uses and gratifications: A paradigm outlined, en Blumler, J. G. y KATZ, E. (eds.). The uses of mass communications: Current perspectives on gratifications research. Beverly Hills, Sage, 269-286.

Rosengren, K. E.; Wenner, L. y Plamgreen, P. (1985) Media Gratification Research. Beverly Hills, CA, Sage.

ROSENGREN, K. E. y WINDAHL, S. (1972) Mass media consumption as a functional alternative, en MCQuaIL, D. (ed.). Sociology of mass communications. Middlesex, Penguin, 166-194.

ROSENTHAL, T. L. y ZIMMERMAN, B. J. (1978) Social learning and cognition. Nueva York, Academic Press.

RuBin, A. M. (1996) Usos y efectos de los media: una perspectiva uso-gratificación, en Bryant, J. y Zillman, D. (comps.). Los efectos de los medios de comunicación. Investigaciones y teorias. Barcelona, Paidós Comunicación, 555-582.

- (2002) The uses-and-gratifications perspectiva of media effects, en BrYANT, J. y Zillman, D. (eds.). Media effects. Advances in theory and research. NJ, Lawrence Erlbaum Associates, 525-548.

Rubin, A. M.; Perse, E. M. y TAYLoR, D. S. (1988) A methodological examination of cultivation, Communication Research, 15, 107-136.

Rubin, A. M. y Windahl, S. (1986) The uses and dependency model of mass communication, Critical Studies in Mass Communication, 3, 184-199.

RudDOCK, A. (2001) Understanding Audiences. Theory and Method. Londres, Sage.

SCHRAMM, W.; LyIE, J. y PARKER, E. (1961) Television in the lives of our children. Stanford, Stanford University Press.

SHAPIRO, L. E. (1997) La inteligencia emocional de los niños. Bilbao, Grupo Zeta.

SIEGEL, A. (1958) The influence of violence in the mass media upon children's role expectations, Child Development, 29, 35-36.

SigNORIELLI, N. (1986) Selective television viewing: A limited possibility, Journal of Communication, 36, 64-75.

Signorielli, N. y Morgan, M. (1990) Cultivation Analysis: New directions in Media Effects Research. Newbury Park, CA, Sage:

Singhal, A. y Rogers, E. M. (1989) Pro-social television for development in India, en Rice, R. E. y AtKin, C. K. (eds.). Public communication campaigns. Newbury Park, Sage, 331-350. 
SNYDER, M. (1980) Seek, and ye shall find: Testing hypotheses about other people, en Higgings, E. T.; Herman, C. P. y Zanna, M. P. (eds.). Social cognition: The Ontario Symposium on Personality and Social Psychology, 1. NJ, Lawrence Erlbaum Associates, $105-130$.

STEPHENSON, W. (1967) The play theory of mass communication. Chicago, University of Chicago Press.

Swanson, D. L. (1977) The uses and misuses of uses and gratifications, Human Communication Research, 3, 214-221.

- (1979) Political communication research and the uses and gratifications model: A critique, Communication Research, 6, 37-53.

Tannenbaum, P. y Zillman, D. (1975) Emotional arousal in the facilitation of aggression through communication, en BERKOwITZ, L. (ed.). Advances in experimental social psychology, 8. New York, Academic Press, 149-182.

Thompson, J. B. (1998) Los media y la modernidad. Una teoria de los medios de comunicación. Barcelona, Paidós.

Vander Zanden, J. W. (1990) Manual de Psicología Social. Barcelona, Paidós.

VILCHES, L. (1999) La televisión: los efectos del bien y del mal. Barcelona, Paidós Ibérica.

WiMmer, R. y DOMINICK, J. (1996) La investigación científica de los medios de comunicación. Una introducción a sus métodos. Barcelona, Bosch.

Windahl, S. (1981) Uses and gratifications at the crossroads, en WilhoIT, G. C. y Debock, G. (eds.). Mass communication review yearbook. Beverly Hills, Sage Publications, 174-185.

WINICK, C. (1988) The functions of TV: life without the Big Box, en OsKamp, S. Television as a social issue. Newbury Park, CA, Sage, 217-237.

Wober, M. y GunTER, B. (1988) Television and social control. Avebury, Aldershot.

Wolf, M. (1987) La investigación de la comunicación de masas. Crítica y perspectivas. Barcelona, Paidós.

- (1994) Los efectos sociales de los media. Barcelona, Paidós.

WRight, C. R. (1960) Functional analysis and mass communication, Public Opinion Quarterly, 24, 605-620.

Zillman, D. (1983) Arousal and Aggression, en Geen, R. y Donnerstein, E. (eds.). Aggression. Theoretical and Methodological Issues. New York, Academic Press, 75-101.

Zillman, D. y Bryant, J. (1982) Pornography, Sexual Callousness, and the Trivialization of Rape, Journal of Communication, 32, 10-21. 